\title{
Article \\ Synthesis and Laccase-Mediated Oxidation of New Condensed 1,4-Dihydropyridine Derivatives
}

\author{
Jelena Milovanovic ${ }^{1,+}+{ }^{\infty}$, Miyase Gözde Gündüz ${ }^{2,+}\left(\mathbb{D}\right.$, Anastasia Zerva $^{3}\left(\mathbb{D}\right.$, Milos Petkovic $^{4}$, \\ Vladimir Beskoski ${ }^{5}{ }^{\circ}$, Nikolaos S. Thomaidis ${ }^{6}\left(\mathbb{D}\right.$, Evangelos Topakas ${ }^{3}(\mathbb{D})$ and Jasmina Nikodinovic-Runic $1, *(\mathbb{C})$
}

1 Institute of Molecular Genetics and Genetic Engineering, University of Belgrade, Vojvode Stepe 444a, 11221 Belgrade, Serbia; jelenaradivojevic@imgge.bg.ac.rs

2 Department of Pharmaceutical Chemistry, Faculty of Pharmacy, Hacettepe University, Sihhiye, 06100 Ankara, Turkey; miyasegunduz@yahoo.com

3 Industrial Biotechnology and Biocatalysis Group, Biotechnology Laboratory, School of Chemical Engineering, National Technical University of Athens, 5 Iroon Polytechniou Str., Zografou Campus, 15780 Athens, Greece; anazer@chemeng.ntua.gr (A.Z.); vtopakas@chemeng.ntua.gr (E.T.)

4 Faculty of Pharmacy, University of Belgrade, Vojvode Stepe 450, 11221 Belgrade, Serbia; milosp@pharmacy.bg.ac.rs

5 Faculty of Chemistry, University of Belgrade, Studentski trg 16, 11158 Belgrade, Serbia; vbeskoski@chem.bg.ac.rs

6 Laboratory of Analytical Chemistry, Department of Chemistry, National and Kapodistrian University of Athens, Panepistimioupolis Zografou, 15771 Athens, Greece; ntho@chem.uoa.gr

* Correspondence: jasmina.nikodinovic@gmail.com or jasmina.nikodinovic@imgge.bg.ac.rs; Tel.: +381-11-397-60-34

check for updates

Citation: Milovanovic, J.; Gündüz, M.G.; Zerva, A.; Petkovic, M.; Beskoski, V.; Thomaidis, N.S.; Topakas, E.; Nikodinovic-Runic, J. Synthesis and Laccase-Mediated Oxidation of New Condensed 1,4-Dihydropyridine Derivatives. Catalysts 2021, 11, 727. https:// doi.org/10.3390/ catal11060727

Academic Editor: Antonio Zuorro

Received: 25 May 2021

Accepted: 10 June 2021

Published: 12 June 2021

Publisher's Note: MDPI stays neutral with regard to jurisdictional claims in published maps and institutional affiliations.

Copyright: (c) 2021 by the authors Licensee MDPI, Basel, Switzerland. This article is an open access article distributed under the terms and conditions of the Creative Commons Attribution (CC BY) license (https:// creativecommons.org/licenses/by/ $4.0 /)$.
+ Equal contribution.

Abstract: We describe herein the synthesis and laccase mediated oxidation of six novel 1,4-dihydropyridine (DHP)-based hexahydroquinolines (DHP1-DHP3) and decahydroacridines (DHP4-DHP6). We employed different laccase enzymes with varying redox potential to convert DHP1-DHP3 and DHP4DHP6 to the corresponding pyridine-containing tetrahydroquinoline and octahydroacridine derivatives, respectively. Intensively coloured products were detected in all biocatalytic reactions using laccase from Trametes versicolor (TvLacc), possibly due to the presence of conjugated chromophores formed in products after oxidation. The NMR assessment confirmed that the oxidation product of DHP1 was its corresponding pyridine-bearing tetrahydroquinoline derivative. Laccase from Bacillus subtillis (BacillusLacc) was the most efficient enzyme for this group of substrates using HPLC assessment. Overall, it could be concluded that DHP2 and DHP5, bearing catecholic structures, were easily oxidized by all tested laccases, while DHP3 and DHP6 containing electron-withdrawing nitro-groups are not readily oxidized by laccases. DHP4 with decahydroacridine moiety consisting of three condensed six-membered rings that contribute not only to the volume but also to the higher redox potential of the substrate rendered this compound not to be biotransformed with any of the mentioned enzymes. Overall, we showed that multiple analytical approaches are needed in order to assess biocatalytical reactions.

Keywords: dihydropyridine; hexahydroquinoline; acridinedione; laccase; biotransformation

\section{Introduction}

1,4-Dihydropyridine (DHP) scaffold occupies a significant position amongst all heterocycles, especially due to its therapeutic value [1]. Commercial DHPs, represented by nifedipine, target the L-type calcium channel and are widely prescribed for the treatment of cardiovascular conditions [2]. This prominent ring is also suitable for various chemical modifications. Introducing DHP into fused ring systems such as hexahydroquinoline and decahydroacridine has led to the discovery of novel molecules with a vast variety of biological activities $[3,4]$. DHPs are under investigation not only for medical purposes 
but also for their physicochemical properties. The oxidation of DHP ring to pyridine is one of the most examined characteristics of DHPs also providing an approach for the preparation of pyridines starting from DHPs [5]. The oxidation of DHPs is of great interest since DHP-based calcium channel blockers are biologically converted to the corresponding pyridine derivatives by the action of cytochrome P-450 in the liver [6,7].

Although a number of catalytic oxidative aromatization of DHPs using molecular oxygen as the oxidant have been reported, many of these methods rely on transition metals, employ organic solvents and require high reaction temperatures [8-10]. On the other hand, laccases (EC 1.10.3.2) are multi-copper oxidoreductases (MCOs), and as such, use the distinctive redox ability of copper ions to catalyze the oxidation of a wide range of aromatic substrates, in parallel with the reduction of molecular oxygen to two water molecules [11].

The rate of a laccase-oxidized reaction has been shown to depend on the redox potential difference $\left(\Delta \mathrm{E}^{0}\right)$ between the enzyme and the substrate. However, other factors such as the size, shape and hydrophobicity of the substrate-binding site near the T1 copper apparently also affect the reaction rate [12]. All laccases can be divided into three groups according to their redox potential $\left(\mathrm{E}^{\circ}\right)$ at the $\mathrm{T} 1 \mathrm{Cu}$ site: (a) low $\mathrm{E}^{\circ}$ enzymes with $\mathrm{E}^{\circ} \approx 430 \mathrm{mV}$ referred to a standard normal hydrogen electrode (NHE); (b) a middle $\mathrm{E}^{\circ}$ group including enzymes with potentials $470-710 \mathrm{mV}$; (c) high $\mathrm{E}^{\circ}$ enzymes with redox potentials of $730-800 \mathrm{mV}$ [13].

Only a few reports on the enzyme-mediated oxidation of DHPs are available, using purified Trametes versicolor laccase (TvLacc) and aerial oxygen, under mild conditions [6,14]. Abdel-Mohsen and coworkers showed that ABTS (2,2'-Azino-bis(3-ethylbenzothiazoline6-sulfonic acid) diammonium salt) is the best mediator for the oxidation of DHPs [6]. A cooperative catalytic system of TvLacc and 4-phenyl urazole has been applied for the aerobic oxidative aromatization of DHPs [15]. In our previous work, Simic et al. showed that recombinant bacterial laccase, BliLacc from Bacillus licheniformis was successfully applied in the preparative oxidation of some DHPs, but the oxidation of DHPs with bulkier side groups resulted in poor yields of the corresponding products [16].

As laccases oxidize phenolic substrates [17], we aimed to synthesize six novels DHPs carrying hydroxyl group(s) on the phenyl ring (Figure 1). Unlike commercial DHPs, we introduced this scaffold into two condensed ring systems; hexahydroquinoline (DHP1DHP3) and decahydroacridine (DHP4-DHP6). We investigated their laccase-mediated oxidation to the corresponding pyridine-containing derivatives using laccase enzymes with different redox potential. To examine the influence of redox potential on the efficiency of biocatalytic reaction, we have used four laccases: Trametes versicolor laccase (TvLacc) $\left(\mathrm{E}^{0}=800 \mathrm{mV}\right)$ [18], Myceliophthora thermophila $\left(\right.$ Novozym $\left.{ }^{\circledR} 51003\right)$ laccase $\left(\mathrm{E}^{0}=460 \mathrm{mV}\right)$ [19], Bacillus subtilis laccase (BacillusLacc) $\left(\mathrm{E}^{0}=525 \mathrm{mV}\right)$ [20] and Thermothelomyces thermophila laccase-like multicopper oxidase $(T t \mathrm{LMCO})\left(\mathrm{E}^{0}=317 \mathrm{mV}\right)$ [21]. Molecular docking analysis was employed for a better understanding of substrate-enzyme interactions.<smiles>[R]c1ccc(C2C(C(=O)OC(C)C)=C(C)NC3=C2C(=O)C(C)(C)CC3)cc1[R]</smiles>

DHP1-DHP3<smiles>[R]c1ccc(C2C3=C(CCC(C)(C)C3=O)NC3=C2C(=O)C(C)(C)CC3)cc1[R]</smiles>

DHP4-DHP6

\begin{tabular}{ccc}
\hline DHP & $\mathbf{R}_{\mathbf{1}}$ & $\mathbf{R}_{\mathbf{2}}$ \\
\hline DHP1 & $\mathrm{OH}$ & $\mathrm{H}$ \\
DHP2 & $\mathrm{OH}$ & $\mathrm{OH}$ \\
DHP3 & $\mathrm{NO}_{2}$ & $\mathrm{OH}$ \\
DHP4 & $\mathrm{OH}$ & $\mathrm{H}$ \\
DHP5 & $\mathrm{OH}$ & $\mathrm{OH}$ \\
DHP6 & $\mathrm{NO}_{2}$ & $\mathrm{OH}$ \\
\hline
\end{tabular}

Figure 1. Chemical structures of the synthesized compounds.

\section{Results and Discussion}

We have successfully synthesized and structurally characterized two small subseries of new condensed DHPs carrying hexahydroquinoline (DHP1-DHP3) and decahydroacridine (DHP4-DHP6) scaffolds. The compounds were synthesized from moderate to good 
yields via modified Hantzsch reaction using 1,3-dicarbonyl compounds, appropriate benzaldehyde and ammonium acetate. The synthetic route to obtain the target compounds is depicted in Figure 2.<smiles>[R]c1ccc(C2C(C(=O)OC(C)C)=C(C)NC3=C2C(=O)C(C)(C)CC3)cc1[R]</smiles>

DHP1-DHP3<smiles>[R]c1ccc(C=O)cc1[R]</smiles><smiles>[R]c1ccc(C2C3=C(CCC(C)(C)C3=O)NC3=C2C(=O)C(C)(C)CC3)cc1[R]</smiles>

DHP4-DHP6

Figure 2. Synthetic scheme for the preparation of DHP-based compounds.

With this approach, we aimed to introduce DHP scaffold into condensed ring systems unlike the structures of the commercial ones such as nifedipine, isradipine and amlodipine. Additionally, we introduced at least one hydroxyl group on the phenyl ring of the compounds since laccases oxidize phenolic substrates. To see the effect of the phenyl substitution pattern on the laccase-mediated oxidation of the compounds, we synthesized compounds carrying one (DHP1, DHP4) or two phenolic hydroxyl groups (DHP2, DHP5). Moreover, we introduced an electron-withdrawing substituent, nitro group, to determine its impact on the oxidation of DHP3 and DHP6.

\subsection{Oxidation of DHPs by Laccases from Trametes versicolor (TvLacc)}

We have recently described the oxidation of a series of DHP derivatives by recombinant bacterial laccase, BliLacc from B. licheniformis [16]. Encouraged with previous results this study was initiated to explore if the commercially available laccase TvLacc could oxidize DHP1-DHP6. It was noticed that all the compounds were insoluble in most of the tested solvents and poorly soluble in warm ethanol and methanol; however, all reaction mixtures, after $18 \mathrm{~h}$ incubation, resulted in the colour change of all reactions: DHP1 and DHP4 turned to purple, DHP2 and DHP5 to orange and DHP3 and DHP6 to green (Figure 3). Notably, despite the colour change, the additional products were detected by TLC only in reaction mixtures containing DHP1 and DHP5 as substrates (Figure 3). The observed colour change indicated that there was a change in the chromophore structure of the starting compounds. Indeed, UV-VIS spectra of both substrate and reaction product confirmed this (Figures S1-S6). We expected that the oxidation of the dihydropyridine ring led to aromatization and formation of a pyridine ring which together with the phenyl group forms a conjugated chromophore. In the control reactions without enzyme and in the presence of ABTS, colour changed to green, due to oxidation of ABTS to the green cation radical (ABTS•+) [22]. In the control reactions without the ABTS as mediator and TvLacc, a slight change of colour in reactions with substrate DHP2 and DHP5 was notable (Figure S7), while TLC and HPLC analysis showed very low conversion rate but the same pattern to reactions in the presence of ABTS (Figures S8-S13, panel f). The addition of 
$\mathrm{CuSO}_{4}$ did not have any influence on resulting products compared to the same reactions without $\mathrm{Cu}$ ions (data not shown).

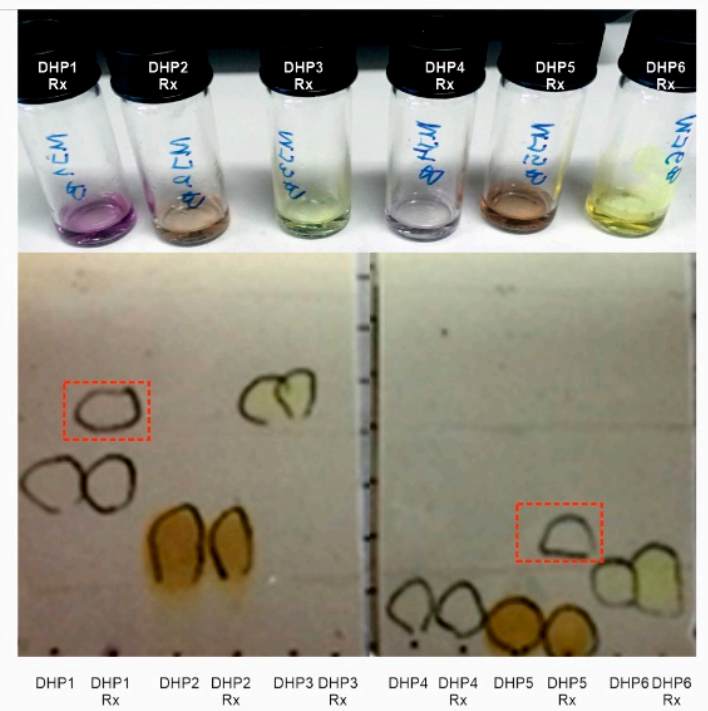

Figure 3. Biocatalytic reactions of DHP1-DHP6 using TvLacc as biocatalyst. Reactions after $18 \mathrm{~h}$ incubation and extraction with ethyl acetate are depicted in the upper panel and thin-layer chromatography analysis of DHP substrates and corresponding biotransformation products (eluent hexane/ethylacetate $=1 / 1$, UV visualization). Red rectangles indicate DHP1 and DH5 reaction products.

Reaction mixtures were analysed by HPLC, as well (Figures S8-S13). We found that the results obtained on HPLC (with a UV detector) are consisted with TLC analysis results. The reactions using only DHP1 and DHP5 gave an additional significant signal, belonging to the product of the biocatalytic reaction, in the corresponding chromatograms.

Reaction product from DHP1 oxidation was successfully isolated and characterized by NMR spectroscopy. The proton NMR spectrum of the starting compound DHP1 contains signals derived from nitrogen-bound hydrogen and C4-hydrogen in the pyridine nucleus at about $\delta \sim 9 \mathrm{ppm}$ and $\delta=4.74$, respectively. These signals do not exist in the ${ }^{1} \mathrm{H}$ NMR spectrum of the product (Figure 4, Figure S14). On the other hand, in the ${ }^{13} \mathrm{C}$ NMR spectrum of the product, an additional signal originating from the carbon $\mathrm{C} 4$ in the aromatic pyridine ring appears in the range from $140 \mathrm{ppm}$ to $170 \mathrm{ppm}$ (Figure S15). Taking into account these differences in the spectra the structure of the obtained reaction product was determined (Figure 4). According to the appearance of the HPLC chromatogram and the retention time (Figure S12, data b), the same transformation was also expected during the reaction with the substrate DHP5. Noteworthy, when DHP5-R was purified on a silica column, hydrolysis of the product occurred, preventing the representative NMR spectrum; however, signature peaks of the expected oxidation product were present (data not shown). When liquid chromatography coupled with a mass detector was used to analyze products of the biocatalytic transformation, it was quite difficult to determine the identity and the amount of the products, as the expected mass difference was only a single $\mathrm{H}$ atom (Figure 4). 


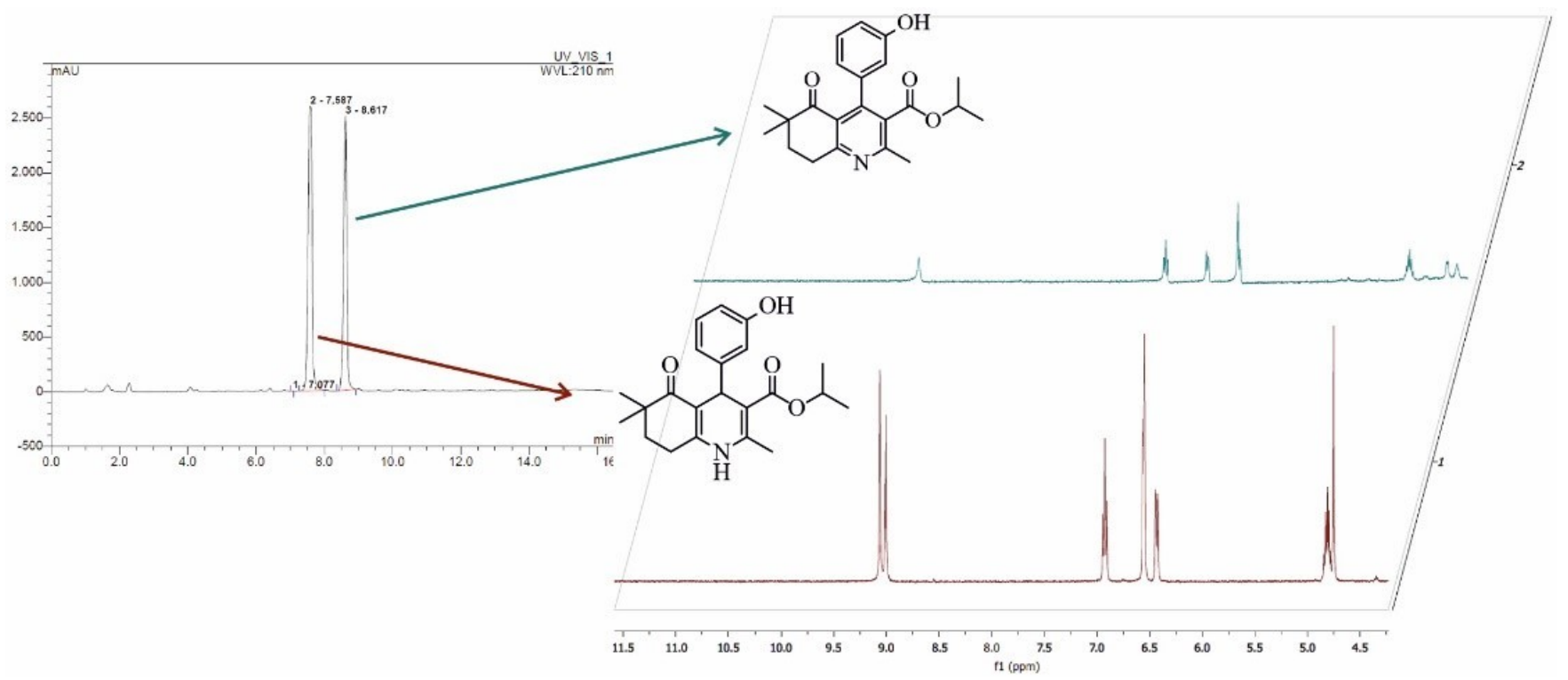

Figure 4. HPLC chromatogram of the laccase mediated transformation of DHP1 showing both DHP1 and DHP1-R as reaction product and ${ }^{1} \mathrm{H}$ NMR spectra of the DHP1 (bottom) and its tetrahydroquinoline derivative as the isolated oxidation product (top).

It has been well established that in the mediator-redox-system, oxidation occurs through a mediator, and it is highly dependent on the type of mediator [23]. Recently, it was shown that, in the presence of ABTS as a mediator, the substrate oxidations by the laccase and by the ABTS cation radical take place simultaneously, at least for phenolic substrates [24]. In order to better understand why oxidation products did not occur in reactions with other substrates, we calculated the relative energies of all substrates and expected pyridines (Table 1). All substrates have higher stability (lower absolute energy) in comparison with the corresponding oxidation products. Substrate-product pair DHP1DHP1R has the lowest energy barrier in comparison with others; this could be the reason for the successful oxidation of DHP1. On the other hand, the reaction product occurs in the oxidation of DHP5 although the relative energy difference is similar to the other substrate-product pairs (Table 1).

Table 1. Relative energies of substrates DHP1-DHP6 and expected reaction products (DHP1-R-6-R).

\begin{tabular}{cc}
\hline Compound & Relative Energy (kcal/mol) \\
\hline DHP1 & $0.0^{a}$ \\
DHP1-R & 750.8 \\
DHP2 & $0.0^{b}$ \\
DHP2-R & 763.2 \\
DHP3 & $0.0^{c}$ \\
DHP3-R & 784.4 \\
DHP4 & $0.0^{d}$ \\
DHP4-R & 763.6 \\
DHP5 & $0.0^{e}$ \\
DHP5-R & 765.8 \\
DHP6 & $0.0^{f}$ \\
DHP6-R & 763.3
\end{tabular}

Absolute energy baselines (in Hartree). $\quad a:-1210.607757755 ; \quad b: \quad-1285.85580863 ; c: \quad-1415.17774797$; $d:-1212.73819921 ; \mathrm{e}:-1287.97793577 ; f:-1417.28900326$.

\subsection{Oxidation of DHPs by Laccases with Different Redox Potential}

After the first set of biocatalytic oxidation of a series of DHP compounds with TvLacc, we found that there was a difference in the success of the reaction with various substrates (Figure 5A). As the progression of the reaction is influenced by many factors, among them enzyme redox potential, we decided to examine biocatalytic oxidation with three 
additional laccases having lower redox potential compared to TvLacc $\left(\mathrm{E}^{0}=800 \mathrm{mV}\right)$, Novozym 51003 laccase $\left(\mathrm{E}^{0}=460 \mathrm{mV}\right)$ [19], BacillusLacc $\left(\mathrm{E}^{0}=525 \mathrm{mV}\right)$ [20], TtLMCO1 $\left(\mathrm{E}^{0}=317 \mathrm{mV}\right)$. Tt $\mathrm{LMCO} 1$ is a novel thermostable laccase-like multicopper oxidase with low redox potential $\left(\mathrm{E}^{0}=317 \mathrm{mV}\right.$ vs. $\mathrm{NHE}$ at $\left.30^{\circ} \mathrm{C}\right)$ [21]. TtLMCO1 has been used previously for the cyclization of chalcones to the respective aurones with satisfactory yields [25]. The low redox potential of this particular LMCO leads to higher selectivity and therefore could be an advantage in synthetic applications, compared to high- $\mathrm{E}^{0}$ laccases, which can quickly polymerize their substrate to insoluble products.

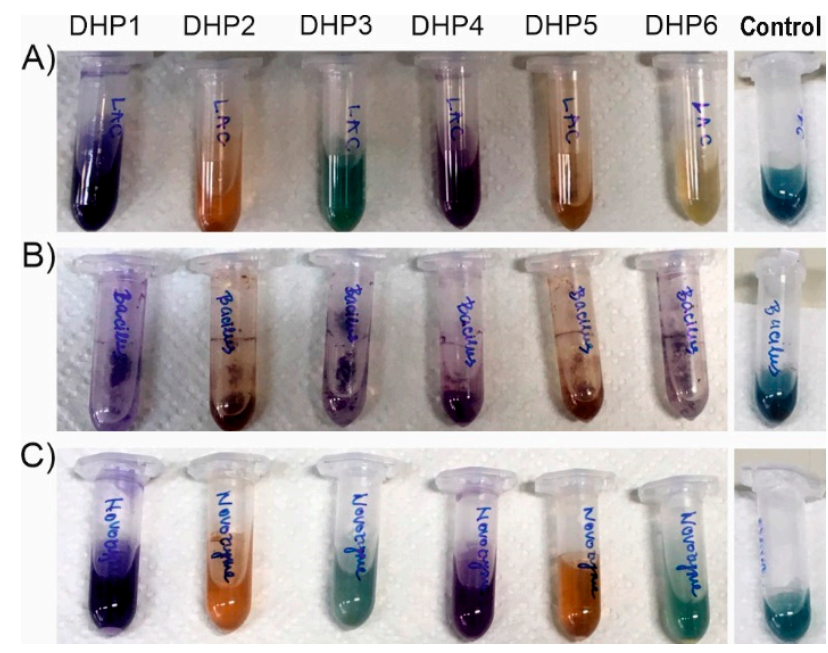

Figure 5. Colours of reactions after $18 \mathrm{~h}$ incubation with different types of laccases (A) TvLacc; (B) BacillusLac; (C) Novozym 51003; Control reactions with enzymes and ABTS mediator without DHP substrate.

Reactions were set by the same general procedure on small scale (using the same ratio of enzyme U/mg of a substrate; Table S1) and analyzed by HPLC after $18 \mathrm{~h}$ incubation (Table 2)). Using DHP4 and DHP6 as substrates, no detectable products were observed with any of the enzymes, although DHP4 changed colour to purple. Similarly, DHP3 was also very difficult to oxidize by laccases and only about $5-6 \%$ of the substrate was converted using BacillusLacc and Novozym 51003 laccases (Table 2). Among all tested enzymes, BacillusLacc was the most successful in the oxidation of DHP1 with more than $45 \%$ of this substrate converted to products, followed by TvLacc $>$ Novozym 51003>TtLMCO1. Judging by the HPLC assessment, the easiest to transform was DHP5 with TtLMCO1 utilising about $80 \%$ of the substrate in the tested time-frame. The biocatalytic reactions without the presence of the ABTS mediator were also assessed (Table S2). Overall, lower conversion has been detected, but substrates DHP1, DHP2 and DHP5 were still the most readily oxidized. On the other hand, it was quite difficult to assess the biocatalytic reaction products using mass spectral analysis as the major expected product differed only in single hydrogen from the substrate, but MS analysis detected dimers in reaction with DHP5 as substrate (Figure S17). Since the detected dimer co-eluted with the respective monomer, it is possible that it could be formed during the ionization process itself (i.e., the dimerization took place after elution from the column). 
Table 2. DHP1-DHP6 biotransformation with four laccases assessed by HPLC with the amount of substrate remaining after $18 \mathrm{~h}$ reaction expressed as \%. Chromatograms are given in supporting material.

\begin{tabular}{ccccc}
\hline $\begin{array}{c}\text { Substrate * } \\
\text { Enzyme }\end{array}$ & DHP1 & DHP2 & DHP3 & DHP5 \\
\hline TvLacc & 61.8 & 45.9 & 100 & 52.8 \\
BacillusLacc & 54.7 & 63.8 & 94.1 & 43.6 \\
Novozym 51003 & 67.2 & 79.4 & 94.1 & 37.7 \\
TtLMCO1 & 79.4 & 76.6 & 100 & 21.2 \\
\hline
\end{tabular}

${ }^{*}$ For reactions DHP4 and DHP6 the results are not shown, since there was no reaction.

DHP3 and DHP6 containing electron-withdrawing nitro-groups are not readily oxidized by laccases [26]; therefore, the absence of activity against $-\mathrm{NO}_{2}$-bearing DHPs could be expected, despite the use of ABTS as mediator. $\mathrm{NO}_{2}$-bearing DHPs were oxidized at very low yield only by BacillusLacc and Novozym 51003, but not TvLacc. This is in accordance with the findings of Tadesse and coworkers, where $\mathrm{NO}_{2}$-bearing phenols were readily oxidized by Novozym laccase, but not TvLacc, despite the difference of the enzymes in $\mathrm{E}^{0}$ and the high $\mathrm{E}^{0}$ of the substrates [19]. The authors attributed this apparent discrepancy to steric issues related to the active site architecture of TvLacc: the existence of two phenylalanines (Phe332 and Phe337), forming a 'gate' for the entrance of the substrate, could prohibit access to bulky substrates. Phe162 also plays an important role in the shaping of the hydrophobic cavity: replacement by Ala resulted in more efficient oxidation of bulky substrates [27]. Small size residues in these positions result in a more relaxed entrance to the T1 copper centre (Figure 6 and Figure S18), which is reflected in more efficient oxidation of bulky substrates by BacillusLacc, compared to the other laccases. On the other hand, Novozym 51003 contains a Trp residue in the position of Phe337 of TvLacc laccase, which is a rather bulky amino acid (Table S2, Figures S12 and S19). This may contribute to the lower oxidation efficiency towards DHP2, compared to BacillusLacc.
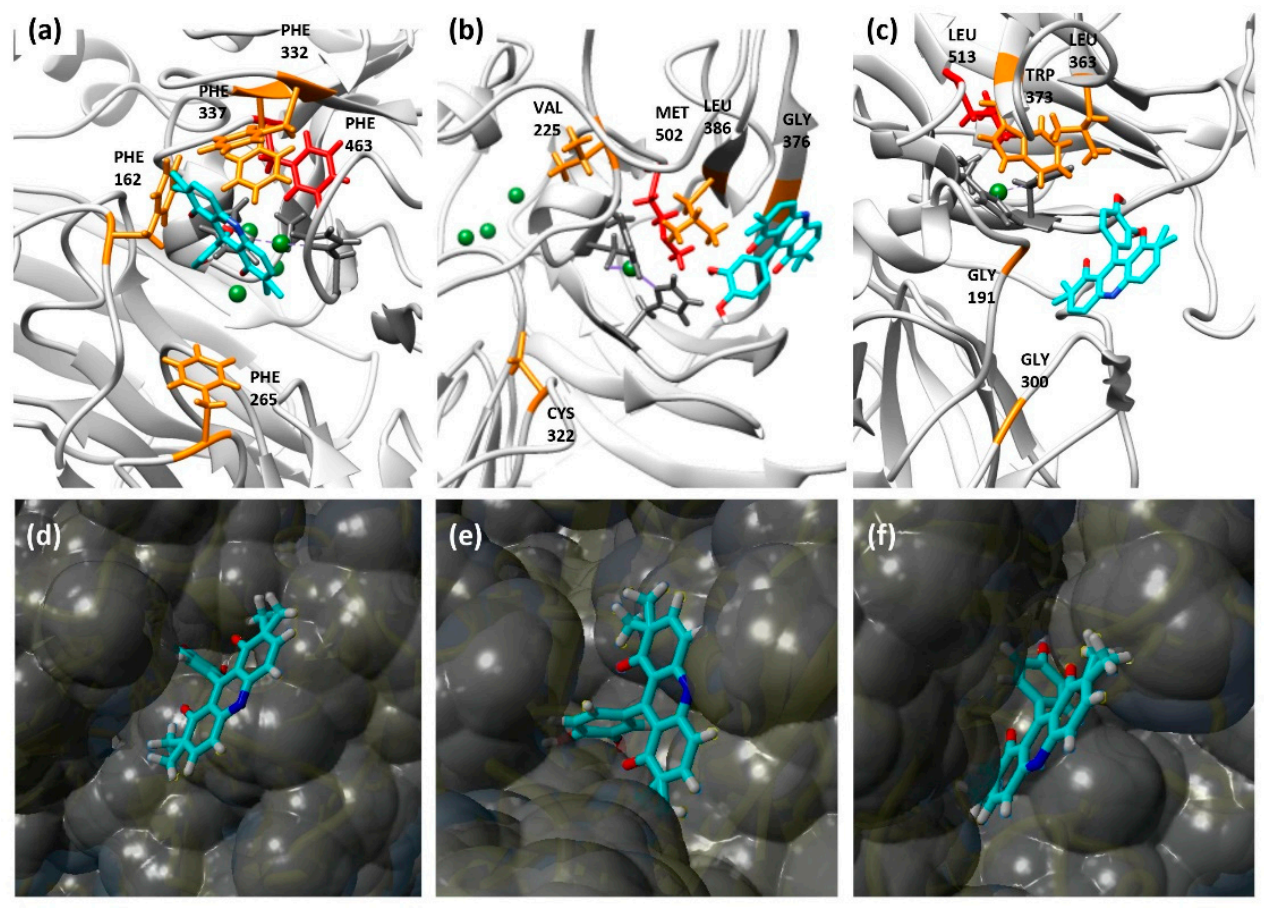

Figure 6. Models of DHP5 interacting with laccases TvLacc (a,d), BacillusLacc (b,e) and Novozym $51003(\mathbf{c}, \mathbf{f}) .(\mathbf{a}-\mathbf{c})$ The interaction model of DHP5 with the tested laccases. Ligand is coloured in cyan, copper atoms are coloured in green, equatorial T1 copper ligands are coloured in dark grey, an axial copper ligand is coloured in red, binding pocket residues are coloured in orange. (d-f) The surface binding model of DHP5 with the tested laccases. 
To better understand the obtained results, we explored the interaction of compounds DHP5 and DHP2 and laccases using standard docking protocols. TtLMCO1 was not included in docking analyses due to a lack of available crystal structure. The architecture of the substrate-binding pocket, together with the respective models are shown in Figure 6 for DHP5 substrate and in Figure S12 for DHP2 substrate. The results of the molecular docking analysis for DHP5 and DHP2 are shown in Tables S3 and S4, respectively.

Some conclusions can be drawn from the correlation of the size of the substrates with the architecture of the substrate pocket for each laccase: for example, according to structurebased sequence alignments, BacillusLacc contains Val, Leu and Gly in the positions Phe 162, Phe337 and Phe332 of TvLacc laccase, respectively, as shown by structure-based sequence alignments (Figure S18).

The redox potential of laccases in some cases can be correlated with one residue, acting as a weakly coordinating axial ligand to the T1 copper centre. This amino acid is usually a Phe in high-redox, white-rot fungal laccases, while in BacillusLacc and Novozym 51003 laccase this position is occupied by a Met and a Leu, respectively (Figure 6) [28]. Even though DHP1 and DHP4 have the same phenol ring, their reactivity with all tested enzymes is completely different. DHP1 is oxidized by all tested laccases in good yield while DHP4 did not react at all. This is expected because of decahydroacridine moiety in DHP4, which consists of three condensed six-membered rings, which contribute to the volume but more importantly to the higher redox potential of the substrate resulting in no detectable oxidation using laccases.

The addition of $-\mathrm{OH}$ groups in the phenol ring lowers the redox potential $\left(\mathrm{E}^{0}\right)$ of the compound (for example the $\mathrm{E}^{0}$ of catechol is $0.53 \mathrm{~V}$ vs. NHE, compared to phenol with $\mathrm{E}^{0}>0.8 \mathrm{~V}$ vs. NHE), and therefore, the oxidation of catecholic compounds is easier by laccases [29]. This is reflected by our results, since DHP2 and DHP5, bearing catecholic structures, were easily oxidized by almost all tested laccases. Among the catecholic substrates tested, significant differences can be observed in the oxidation efficiency by different laccases: For example, the oxidation of DHP2 follows the $\mathrm{E}^{0}$ of the tested enzymes (less substrate remaining with increasing $\mathrm{E}^{0}$ ), but the exact opposite happens in the case of DHP5 substrate. This is surprising: in the case of TtLMCO1, which is the enzyme with the lowest $\mathrm{E}^{0}$ tested, the maximum activity was observed. Nonetheless, it is in line with previous studies, reporting that substrate specificity does not always correlate well with the redox potential of the enzyme, and kinetic factors also play a significant role. For example, $\mathrm{Xu}$ and co-workers tested the kinetic properties of several multicopper oxidases and concluded that enzyme affinity is independent of the redox potential, although the turnover number is increasing with increased $\mathrm{E}^{0}$ [30]. More recently, Mehra and co-workers concluded that the apparent $\mathrm{K}_{\mathrm{m}}$ of a given laccase is the result of both affinity and electronic properties of the substrate [31]. Glazunova and co. also reported that high $\mathrm{E}^{0}$ does not necessarily lead to more efficient oxidation, and they attributed the observed discrepancies to the architecture of the substrate-binding pocket [32]. According to this study, both the size and flexibility of the substrate pocket, together with the presence of specific amino acids, could determine the affinity for a specific substrate, and thus the architecture of the substrate pocket can be engineered properly to yield tailored biocatalysts for specific applications.

\section{Materials and Methods}

\subsection{Reagents and Chemicals}

All chemicals and solvents were purchased from commercial sources and were used without further purification.

TvLacc was purchased from Sigma (Munich, Germany), provided in the form of powder. Recombinant Bacillus subtilis CotA laccase preparation was obtained as described [33]. TtLMCO1 was heterologously produced in Pichia pastoris and purified with metal affinity chromatography according to our previous study [25]. Laccase from Myceliophthora thermophila (Novozym 51003) was a kind gift from Novozymes A/S ${ }^{\circledR}$ (Bagsværd, Denmark) and was used as supplied. 


\subsection{Analytical Methods}

The reactions were monitored and the purity of the obtained compounds was initially checked by thin-layer chromatography (TLC) performed on silica gel 60 F254 precoated aluminium sheets (Merck, (Darmstadt, Germany) using mobile phase ethyl acetate-hexane (1:1) and UV light for visualization. Melting points were determined using Thomas Hoover Capillary Melting Point Apparatus (Philadelphia, PA, USA) and were uncorrected. ${ }^{1} \mathrm{H}$ and ${ }^{13} \mathrm{C}$ NMR spectra were recorded at 400 and $100 \mathrm{MHz}$, respectively, using HighPerformance Digital FT-NMR Spectrometer, Varian Mercury 400, (Palo Alto, California, USA) in dimethylsulfoxide (DMSO- $d_{6}$ ) solutions. Chemical shifts are expressed in ppm ( $\delta$ ) using tetramethylsilane as an internal standard, and coupling constants (J) are measured in hertz (Hz). The ESI-MS spectra were obtained on a micro mass ZQ-4000 single quadrupole mass spectrometer (Waters, Eschborn, Germany). Elemental analyses were carried out on a Leco CHNS 932 Elemental Analyzer (St. Joesph, MI, USA). UV-VIS spectra were recorded at spectrophotometer Ultrospec 3300pro, Amersham Biosciences (Amersham, Buckinghamshire, UK). Chromatographic analyzes were performed on HPLC (Thermo Scientific Ultimate 3000, Thermo Scientific, Waltham, Massachusetts, USA) with a UV detector (UltiMate 3000 DAD) .

\subsection{General Procedure for the Synthesis and Structure Elucidation of DHPs}

DHP-based compounds (DHP1-DHP6) were obtained according to modified Hantzsch synthesis. DHP-based hexahydroquinolines (DHP1-DHP3) and decahydroacridines (DHP4DHP6) were synthesized as follows:

DHP1-DHP3: Equimolar amount (1 mmol) of 4,4-dimethyl-1,3-cyclohexanedione, substituted benzaldehyde and isopropyl acetoacetate were dissolved in $15 \mathrm{~mL}$ absolute ethanol and heated for $8 \mathrm{~h}$ under reflux conditions. The reaction mixture was cooled and poured into ice water. The obtained precipitate was filtered, and this crude solid was purified by recrystallization from ethanol-water.

DHP4-DHP6: 2 mmol 4,4-dimethyl-1,3-cyclohexanedione, 1 mmol substituted benzaldehyde and an excess amount of ammonium acetate $(5 \mathrm{mmol})$ were heated in $15 \mathrm{~mL}$ absolute ethanol under reflux conditions for $8 \mathrm{~h}$. After the reaction mixture was cooled down, the forming crystals were filtered and washed with cold ethanol, or the mixture was poured into ice-water, the obtained precipitate was filtered and recrystallized from the ethanol-water mixture.

Isopropyl 4-(3-hydroxyphenyl)-2,6,6-trimethyl-5-oxo-1,4,5,6,7,8-hexahydroquinoline-3- carboxylate (DHP1): Yield: $34 \%$. M.p. $229-231{ }^{\circ} \mathrm{C} .{ }^{1} \mathrm{H}-\mathrm{NMR}\left(\delta, \mathrm{DMSO}-\mathrm{d}_{6}\right): 0.88(3 \mathrm{H} ; \mathrm{s}), 0.95$ $(3 \mathrm{H} ; \mathrm{s}), 1.05(3 \mathrm{H} ; \mathrm{d} ; J=6.4 \mathrm{~Hz}), 1.15(3 \mathrm{H} ; \mathrm{d} ; J=6.4 \mathrm{~Hz}), 1.67-1.71(2 \mathrm{H} ; \mathrm{m}), 2.22(3 \mathrm{H} ; \mathrm{s})$, 2.44-2.48 (2H; m), $4.74(1 \mathrm{H} ; \mathrm{s}), 4.77-4.83(1 \mathrm{H} ; \mathrm{m}), 6.41-6.93(4 \mathrm{H} ; \mathrm{m}), 8.97(1 \mathrm{H} ; \mathrm{s}), 9.02(1 \mathrm{H}$; s). ESI-MS $(m / z): 392[\mathrm{M}+\mathrm{Na}]^{+}$. Anal. Calcd. for $\mathrm{C}_{22} \mathrm{H}_{27} \mathrm{NO}_{4} ; \mathrm{C}, 71.52 ; \mathrm{H}, 7.37 ; \mathrm{N}, 3.79$. Found: $\mathrm{C}, 71.25 ; \mathrm{H}, 7.44 ; \mathrm{N}, 3.82$.

Isopropyl 4-(3,4-dihydroxyphenyl)-2,6,6-trimethyl-5-oxo-1,4,5,6,7,8-hexahydro quinoline3-carboxylate (DHP2): Yield: $32 \%$. M.p. $242-244{ }^{\circ} \mathrm{C} .{ }^{1} \mathrm{H}-\mathrm{NMR}\left(\delta, \mathrm{DMSO}-d_{6}\right): 0.90(3 \mathrm{H} ; \mathrm{s})$, $0.97(3 \mathrm{H} ; \mathrm{s}), 1.08(3 \mathrm{H} ; \mathrm{d} ; J=6.4 \mathrm{~Hz}), 1.17(3 \mathrm{H} ; \mathrm{d} ; J=6.4 \mathrm{~Hz}), 1.69-1.73(2 \mathrm{H} ; \mathrm{m}), 2.22(3 \mathrm{H} ; \mathrm{s})$, 2.45-2.49 (2H; m), $4.66(1 \mathrm{H} ; \mathrm{s}), 4.79-4.85(1 \mathrm{H} ; \mathrm{m}), 6.38(1 \mathrm{H} ; \mathrm{dd} ; J=2.0 / 8.0 \mathrm{~Hz}), 6.49(1 \mathrm{H} ; \mathrm{d}$; $J=8.0 \mathrm{~Hz}), 6.54(1 \mathrm{H} ; \mathrm{d} ; J=2.0 \mathrm{~Hz}), 8.45(1 \mathrm{H} ; \mathrm{s}), 8.53(1 \mathrm{H} ; \mathrm{s}), 8.92(1 \mathrm{H} ; \mathrm{s})$. ESI-MS $(m / z): 408$ $[\mathrm{M}+\mathrm{Na}]^{+}$. Anal. Calcd. for $\mathrm{C}_{22} \mathrm{H}_{27} \mathrm{NO}_{5} ; \mathrm{C}, 68.55 ; \mathrm{H}, 7.06 ; \mathrm{N}, 3.63$. Found: $\mathrm{C}, 68.38 ; \mathrm{H}, 7.11$; $\mathrm{N}, 3.62$.

Isopropyl 4-(4-hydroxy-3-nitrophenyl)-2,6,6-trimethyl-5-oxo-1,4,5,6,7,8-hexahydro quinoline3-carboxylate (DHP3): Yield: $65 \%$. M.p. $256-258{ }^{\circ} \mathrm{C} .{ }^{1} \mathrm{H}-\mathrm{NMR}\left(\delta, \mathrm{DMSO}-d_{6}\right): 0.86(3 \mathrm{H} ; \mathrm{s})$, $0.95(3 \mathrm{H} ; \mathrm{s}), 1.02(3 \mathrm{H} ; \mathrm{d} ; J=6.4 \mathrm{~Hz}), 1.16(3 \mathrm{H} ; \mathrm{d} ; J=6.4 \mathrm{~Hz}), 1.66-1.72(2 \mathrm{H} ; \mathrm{m}), 2.24(3 \mathrm{H}$; s), $2.45-2.49(2 \mathrm{H} ; \mathrm{m}), 4.75(1 \mathrm{H} ; \mathrm{s}), 4.77-4.83(1 \mathrm{H} ; \mathrm{m}), 6.95(1 \mathrm{H} ; \mathrm{d} ; J=8.8 \mathrm{~Hz}), 7.28(1 \mathrm{H} ; \mathrm{dd}$; $J=2.0 / 8.8 \mathrm{~Hz}), 7.57(1 \mathrm{H} ; \mathrm{d} ; J=2.0 \mathrm{~Hz}), 9.09(1 \mathrm{H} ; \mathrm{s})$. ESI-MS $(\mathrm{m} / \mathrm{z}): 437[\mathrm{M}+\mathrm{Na}]^{+}$. Anal. Calcd. for $\mathrm{C}_{22} \mathrm{H}_{26} \mathrm{~N}_{2} \mathrm{O}_{6} ; \mathrm{C}, 63.76 ; \mathrm{H}, 6.32 ; \mathrm{N}$, 6.76. Found: $\mathrm{C}, 63.31 ; \mathrm{H}, 6.29 ; \mathrm{N}, 6.76$. 9-(3-hydroxyphenyl)-2,2,7,7-tetramethyl-3,4,6,7,9,10-hexahydroacridine-1,8(2H,5H) -dione (DHP4): Yield: $25 \%$. M.p. $294-295^{\circ} \mathrm{C} .{ }^{1} \mathrm{H}-\mathrm{NMR}\left(\delta\right.$, DMSO- $\left.d_{6}\right): 0.91(6 \mathrm{H} ; \mathrm{s}), 0.97(6 \mathrm{H} ; \mathrm{s})$, 
1.71-1.75 (4H; m), 2.49-2.53 (4H; m), 4.79 (1H; s), 6.37-6.90 (4H; m), 9.01 (1H; s), 9.29 (1H; s). ESI-MS $(m / z): 388[\mathrm{M}+\mathrm{Na}]^{+}$. Anal. Calcd. for $\mathrm{C}_{23} \mathrm{H}_{27} \mathrm{NO}_{3} ; \mathrm{C}, 75.59 ; \mathrm{H}, 7.45 ; \mathrm{N}, 3.83$. Found: C, 75.43; H, 7.39; N, 3.80.

9-(3,4-dihydroxyphenyl)-2,2,7,7-tetramethyl-3,4,6,7,9,10-hexahydroacridine-1,8 (2H,5H)dione (DHP5): Yield: 39\%. M.p. $260-261{ }^{\circ} \mathrm{C} .{ }^{1} \mathrm{H}-\mathrm{NMR}\left(\delta, \mathrm{DMSO}-d_{6}\right): 0.89(6 \mathrm{H} ; \mathrm{s}), 0.94(6 \mathrm{H}$; s), $1.70(4 \mathrm{H} ; \mathrm{t}), 2.47(4 \mathrm{H} ; \mathrm{t}), 4.68(1 \mathrm{H} ; \mathrm{s}), 6.32(1 \mathrm{H} ; \mathrm{dd} ; J=2.0 / 8.0 \mathrm{~Hz}), 6.44(1 \mathrm{H} ; \mathrm{d} ; J=8.0 \mathrm{~Hz})$, $6.52(1 \mathrm{H} ; \mathrm{d} ; J=2.0 \mathrm{~Hz}), 8.34(1 \mathrm{H} ; \mathrm{s}), 8.50(1 \mathrm{H} ; \mathrm{s}), 9.19(1 \mathrm{H} ; \mathrm{s})$. ESI-MS $(\mathrm{m} / \mathrm{z}): 404[\mathrm{M}+\mathrm{Na}]^{+}$. Anal. Calcd. for $\mathrm{C}_{23} \mathrm{H}_{27} \mathrm{NO}_{4} ; \mathrm{C}, 72.42 ; \mathrm{H}, 7.13 ; \mathrm{N}, 3.67$. Found: C, 72.20; H, 7.07; N, 3.69. 9-(4-hydroxy-3-nitrophenyl)-2,2,7,7-tetramethyl-3,4,6,7,9,10-hexahydroacridine-1,8 (2H,5H)dione (DHP6): Yield: 58\%. M.p. $267-268{ }^{\circ} \mathrm{C} .{ }^{1} \mathrm{H}-\mathrm{NMR}\left(\delta, \mathrm{DMSO}-d_{6}\right): 0.87(6 \mathrm{H} ; \mathrm{s}), 0.95(6 \mathrm{H}$; s), 1.69-1.73 (4H; m), 2.47-2.52 (4H; m), $4.77(1 \mathrm{H} ; \mathrm{s}), 6.92(1 \mathrm{H} ; \mathrm{d} ; J=8.4 \mathrm{~Hz}), 7.30$ (1H; dd; $J=2.4 / 8.4 \mathrm{~Hz}), 7.52(1 \mathrm{H} ; \mathrm{d} ; J=2.4 \mathrm{~Hz}), 9.38(1 \mathrm{H} ; \mathrm{s})$. ESI-MS $(m / z): 433$ [M+Na] $]^{+}$Anal. Calcd. for $\mathrm{C}_{23} \mathrm{H}_{26} \mathrm{~N}_{2} \mathrm{O}_{5} ; \mathrm{C}, 67.30 ; \mathrm{H}, 6.38 ; \mathrm{N}, 6.82$. Found: $\mathrm{C}, 67.43 ; \mathrm{H}, 6.43 ; \mathrm{N}, 6.89$.

\subsection{Biocatalytic Reaction Setup and Analytical Procedures}

\subsubsection{General Procedure for the Laccase-Catalyzed Oxidation of DHPs -Analytical Scale}

In $2 \mathrm{~mL}$ Eppendorf tubes, $1 \mathrm{mg}$ of DHP substrate was suspended in $50 \mu \mathrm{L}$ methanol and $850 \mu \mathrm{L}$ sodium acetate buffer $(0.1 \mathrm{M}, \mathrm{pH}=4.5)$. Subsequently, $5 \mu \mathrm{L}$ of ABTS diammonium salt (final concentration $0.2 \mathrm{mM}$ ) dissolved in acetate buffer, and $100 \mu \mathrm{L} \mathrm{TvLacc}$ laccase (4-5 U) dissolved in acetate buffer, was added to the suspension. In some cases, a water solution of $\mathrm{CuSO}_{4}$ to a final concentration of $0.09 \mathrm{mM}$ was also added to the reaction mixture. Reaction mixtures were set up in Thermomixer (Eppendorf, Hamburg, Germany) (rpm 500), $50{ }^{\circ} \mathrm{C}$ overnight. After extraction with ethyl acetate $(3 \times 300 \mu \mathrm{L})$, the solvent was removed under reduced pressure. The crude products were dissolved in methanol, filtered and analyzed with HPLC.

\subsubsection{General Procedure for the Laccase-Catalyzed Oxidation of DHPs -Medium Scale}

In $100 \mathrm{~mL}$ flasks, $5 \mathrm{mg}$ of DHP substrate was suspended in $300 \mu \mathrm{L}$ methanol and $4.5 \mathrm{~mL}$ sodium acetate buffer $(0.1 \mathrm{M}, \mathrm{pH}=4.5)$. Subsequently, $87.5 \mu \mathrm{L}$ ABTS diammonium salt (final concentration $0.2 \mathrm{mM}$ ) dissolved in acetate buffer and $200 \mu \mathrm{L}$ TvLacc (5 U per $1 \mathrm{mg}$ of the substrate) dissolved in acetate buffer was added to the suspension. When all different laccases were used, the amount of enzyme per mg of the substrate was kept constant (the activity units of laccases were assessed against catechol in the sodium acetate buffer $(0.1 \mathrm{M}, \mathrm{pH}=4.5))$. Reaction mixtures were set up in a water bath at $150 \mathrm{rpm}, 50{ }^{\circ} \mathrm{C}$ overnight. (New Brunswick Scientific, Edison, New JerseyUSA). Reaction products were extracted with ethyl acetate $(3 \times 10 \mathrm{~mL})$; the combined organic extracts were dried over anhydrous $\mathrm{MgSO}_{4}$; the solvent was removed under reduced pressure.

\subsubsection{HPLC Analysis of Reaction Mixtures}

Prepared crude products of all reaction mixtures were dissolved in methanol, filtered and analyzed by HPLC (Thermo Scientific Ultimate 3000, Vertex plus C18A $150 \times 4.6 \mathrm{~mm}$ column, Thermo Scientific, Waltham, Massachusetts, USA) using eluent acetonitrile/water in gradient (acetonitrile 30\% to $90 \%$ for $13 \mathrm{~min}, 90 \%$ constant for $0.5 \mathrm{~min}$, return $3 \mathrm{~min}$ to initial conditions). The eluted products were detected at $210 \mathrm{~nm}$, and quantitative analysis was performed by calculating the peak areas into a percentage using Chromeleon software. Reaction products were isolated on a semi-preparative column (Vertex plus C18, $250 \times 8 \mathrm{~mm}$ ) with the same solvent system.

\subsubsection{NMR Analysis of Isolated Product from Biocatalytic Oxidation of DHP1}

The reaction product was isolated using HPLC, as we described in the previous section. NMR spectra were recorded in DMSO- $d_{6}$ solution.

Isopropyl 4-(3-hydroxyphenyl)-2,6,6-trimethyl-5-oxo-5,6,7,8-tetrahydroquinoline-3- carboxylate: ${ }^{1} \mathrm{H}-\mathrm{NMR}\left(\delta, \mathrm{DMSO}-d_{6}\right): 9.45(\mathrm{~s}, 1 \mathrm{H}), 7.10(\mathrm{t}, J=7.7 \mathrm{~Hz}, 1 \mathrm{H}), 6.71(\mathrm{~d}, J=7.3 \mathrm{~Hz}$, $1 \mathrm{H}), 6.40(\mathrm{~d}, J=7.9 \mathrm{~Hz}, 1 \mathrm{H}), 4.79(\mathrm{dd}, J=12.3,6.1 \mathrm{~Hz}, 1 \mathrm{H}), 3.10(\mathrm{t}, J=6.2 \mathrm{~Hz}, 2 \mathrm{H}), 2.45(\mathrm{~s}$, 
$3 \mathrm{H}), 1.94(\mathrm{t}, J=6.4 \mathrm{~Hz}, 2 \mathrm{H}), 1.06(\mathrm{~s}, 3 \mathrm{H}), 0.94(\mathrm{~d}, J=6.2 \mathrm{~Hz}, 3 \mathrm{H}) .{ }^{13} \mathrm{C}$ NMR $\left(\delta\right.$, DMSO- $\left.d_{6}\right)$ : 201.74, 166.81, 163.39, 157.16, 156.86, 148.45, 138.91, 129.94, 129.17, 123.73, 118.69, 115.02, $114.81,69.19,42.58,34.59,29.51,24.09,22.96,21.38$.

\subsection{Molecular Docking Simulations}

The protein database (PDB) structures selected for docking analyses were 1KYA for TvLacc, 4Q8B for BacillusLacc and 6F5K for Novozym 51003 laccase. TtLMCO1 was not included in docking analyses due to a lack of available crystal structure. The structures were optimized, and co-crystallized ligands were removed. Molecular docking analyses were performed with YASARA (Yet Another Scientific Artificial Reality Application), with a simulation cell of $13.0 \AA$ filled with water around T1 copper [34]. The receptor was considered rigid, and the ligand was considered flexible. All other parameters were set to defaults. After 25 AutoDock VINA runs, the resulting clusters with RMSD > 5.0 ̊̊ were visually inspected. The complex conformations with the highest binding energies were selected, and visualization of the resulting models was performed with UCSF Chimera 1.14, which was also used for structure-based sequence alignments. Structure-based sequence alignments were visualized by ESPRIPT 3.0.

Molecular Energies Calculations

Optimization of geometry and calculation of relative energies $(\mathrm{kcal} / \mathrm{mol})$ of compounds DHP1-DHP6 and expected reaction products were obtained by Gaussian with B3LYP method using a 6-311++G(d,p) basis set.

\section{Conclusions}

Laccase oxidation usually leads to the formation of multiple products, and thus, laccase-mediated biocatalytic reactions require the use of multiple approaches for their characterization. In the present work, the laccase-mediated biocatalytic transformation of new DHP molecules was described. DHP2 and DHP5, which contain catechol structures, were easily oxidized by all tested laccases, while DHP3 and DHP6, which contain electronwithdrawing nitro-groups, are not readily oxidized, even with the addition of ABTS as mediator. The presence of a voluminous acridine ring, as well as the reportedly higher redox potential of the phenolic hydroxyl group in DHP4 contributed to the small reactivity of this compound. From the results of the present study, it can be concluded that molecular descriptors, such as size and electronic properties, have the greatest influence on the susceptibility of DHP-based substrates to laccase oxidation. Molecular docking analysis suggests that the architecture of the substrate-binding pocket is important for efficient oxidation. BacillusLacc has small gate-forming residues compared to the other tested laccases, and this enzyme was shown to be the most versatile regarding DHP oxidation, since it showed satisfactory activity against all tested DHP substrates. Overall, the present work reports the synthesis and laccase-mediated oxidation of new DHP compounds. The results of the present study highlight the complexity of laccase-mediated oxidation, and complement previous studies, supporting that the redox and kinetic properties of a given laccase may not always be adequate predictors of the activity on a given substrate, since other factors also may play a defining role, such as the size and side groups.

Supplementary Materials: The following are available online at https:/ / www.mdpi.com/article / 10.3390 / catal11060727/s1. Figure S1: DHP1 (a) wave scan 220-800 nm, starting compound from 290-410 nm (concentrated sample dissolved in $\mathrm{MeOH}$, recorded at spectrophotometer); (b) wave scan 200-400 nm, starting compound from 313-400 nm (sample conc. $1 \mathrm{mg} / \mathrm{mL}$, dissolved in $\mathrm{MeOH}$, recorded at HPLC); (c) wave scan 200-400 nm, reaction product -peak of product (blue line) (sample conc. $1 \mathrm{mg} / \mathrm{mL}$, dissolved in MeOH). Figure S2: DHP2 (a) wave scan 220-800 nm, starting compound from 290-410 nm (concentrated sample dissolved in $\mathrm{MeOH}$, recorded at spectrophotometer); (b) wave scan 200-400 nm, starting compound from 313-400 nm (sample conc. $1 \mathrm{mg} / \mathrm{mL}$, dissolved in $\mathrm{MeOH}$, recorded at HPLC); (c) wave scan 200-400 nm, reaction product (sample conc. $1 \mathrm{mg} / \mathrm{mL}$, dissolved in $\mathrm{MeOH}$, recorded at HPLC). Figure S3: DHP3 (a) wave scan 220-800 nm, starting compound from 290-410 nm (concentrated sample dissolved in $\mathrm{MeOH}$, recorded at spectrophotometer); (b) wave 
scan 200-400 nm, starting compound from 313-400 nm (sample conc. $1 \mathrm{mg} / \mathrm{mL}$, dissolved in $\mathrm{MeOH}$, recorded at HPLC); (c) wave scan 200-400 nm, reaction product (sample conc. $1 \mathrm{mg} / \mathrm{mL}$, dissolved in $\mathrm{MeOH}$ ). Figure S4: DHP4 (a) wave scan 220-800 nm, starting compound from 290$410 \mathrm{~nm}$ (concentrated sample dissolved in $\mathrm{MeOH}$, recorded at spectrophotometer); (b) wave scan 200-400 nm, starting compound from 313-400 nm (sample conc. $1 \mathrm{mg} / \mathrm{mL}$, dissolved in $\mathrm{MeOH}$, recorded at HPLC); (c) wave scan 200-400 nm, reaction product (sample conc. $1 \mathrm{mg} / \mathrm{mL}$, dissolved in $\mathrm{MeOH}$, recorded at HPLC). Figure S5: DHP5 (a) wave scan 220-800 nm, starting compound from 290-410 nm (concentrated sample dissolved in $\mathrm{MeOH}$, recorded at spectrophotometer); (b) wave scan 200-400 nm, starting compound from 313-400 nm (sample conc. $1 \mathrm{mg} / \mathrm{mL}$, dissolved in $\mathrm{MeOH}$, recorded at HPLC); (c) wave scan 200-400 nm, reaction product (sample conc. $1 \mathrm{mg} / \mathrm{mL}$, dissolved in $\mathrm{MeOH}$, recorded at HPLC). Figure S6: DHP6 a) wave scan 220-800 nm, starting compound from 290-410 nm (concentrated sample dissolved in $\mathrm{MeOH}$, recorded at spectrophotometer); (b) wave scan 200-400 nm, starting compound from 313-400 nm (sample conc. $1 \mathrm{mg} / \mathrm{mL}$, dissolved in $\mathrm{MeOH}$, recorded at HPLC); (c) wave scan 200-400 nm, reaction product (sample conc. $1 \mathrm{mg} / \mathrm{mL}$, dissolved in $\mathrm{MeOH}$, recorded at HPLC). Figure S7: Colors of reactions after $18 \mathrm{~h}$ incubation with TvLacc without ABTS mediator using six different DHP substrates. Figure S8: HPLC chromatograms of DHP1 before (a) and after oxidation with different enzymes (b) TvLacc, (c) BacillusLacc, (d) Novozym51003, (e) TtLMCO1 and (f) TvLacc without ABTS. Figure S9: HPLC chromatograms of DHP2 before (a) and after oxidation with different enzymes (b) TvLacc, (c) BacillusLacc, (d) Novozym51003 (e) TtLMCO1 and (f) TvLacc without ABTS. Figure S10: HPLC chromatograms of DHP3 before (a) and after oxidation with different enzymes (b) TvLacc, (c) BacillusLacc, (d) Novozym51003, (e) TtLMCO1 and (f) TvLacc without ABTS. Figure S11: HPLC chromatograms of DHP4 before (a) and after oxidation with different enzymes (b) TvLacc, (c) BacillusLacc, (d) Novozym51003, (e) TtLMCO1 and f) TvLacc without ABTS. Figure S12: HPLC chromatograms of DHP5 before (a) and after oxidation with different enzymes b) TvLacc, (c) BacillusLacc, (d) Novozym51003, (e) TtLMCO1 and (f) TvLacc without ABTS. Figure S13: HPLC chromatograms of DHP6 before (a) and after oxidation with different enzymes (b) TvLacc, (c) BacillusLacc, (d) Novozym51003, (e) TtLMCO1 and (f) TvLacc without ABTS. Figure S14: ${ }^{1} \mathrm{H}$ NMR spectra of isolated product from biocatalytic oxidation of DHP1. Figure S15: ${ }^{13} \mathrm{C}$ NMR spectra of isolated product from biocatalytic oxidation of DHP1. Figure S16: 2D COSY NMR spectra of isolated product from biocatalytic oxidation of DHP1. Figure S17: (a) Overlaid chromatograms of DHP5 (in blue, for the $\mathrm{m} / \mathrm{z}$ value $382.2013( \pm 5 \mathrm{mDa}$ ) and its corresponding dimer (in orange, for the $\mathrm{m} / \mathrm{z}$ value $763.3952( \pm 5 \mathrm{mDa}$ ) eluted at $6.80 \mathrm{~min}$ in positive ionization mode. (b) MS/MS spectra of the dimer of DHP5 in autoMS mode. Figure S18: Structure-based sequence alignment of laccases from T. versicolor (1kya), B. subtilis (4q8b) and Novozym 51003 (6f5k). Green arrows indicate the gate-forming phenylalanines in laccase from $T$. versicolor. Conserved residues are shown in red. $\alpha$ - helices, $\beta$-sheets and turns are indicated in black. Figure S19: Models of DHP2 interacting with laccases TvLacc (a, d), BacillusLacc (b, e) and Novozym 51003 (c, f). a-c: The interaction model of DHP2 with the tested laccases. Ligand is coloured in cyan, copper atoms are coloured in green, equatorial T1 copper ligands are coloured in dark grey, an axial copper ligand is coloured in red, binding pocket residues are coloured in orange. d-f: The surface binding model of DHP2 with the tested laccases. Table S1: Specific activities of the different laccases used in this study. Table S2: DHP1-DHP6 biotransformation with four laccases, without mediator ABTS, assessed by HPLC with the amount of substrate remaining after $18 \mathrm{~h}$ reaction expressed as \%. (Chromatograms for TvLacc are provided in Figures S2-S7 as panel (f)). Table S3: The results of molecular docking for DHP5 in the active site of the tested laccases. Table S4: The results of molecular docking for DHP2 in the active site of the tested laccases.

Author Contributions: Conceptualization, J.M., E.T. and J.N.-R. methodology, J.M, M.G.G., A.Z. and N.S.T.; investigation, J.M., M.G.G., A.Z., M.P. and V.B.; resources, V.B., N.S.T., E.T. and J.N.-R.; data curation, J.M., M.G.G., A.Z.; writing—original draft preparation, J.M., A.Z. and M.P.; writing—review and editing, M.G.G., V.B., N.S.T., E.T. and J.N.-R.; funding acquisition, J.N.-R. All authors have read and agreed to the published version of the manuscript.

Funding: This research was funded by Ministry of Education, Science and Technological Development of the Republic of Serbia, 451-03-68/2020-14/200042, 2020.

Acknowledgments: The authors are grateful to Novozymes A/S for the generous gift of Novozym ${ }^{\circledR}$ 51003. M.G.G. gratefully acknowledges the financial support provided by the BAGEP Award of the Science Academy. 
Conflicts of Interest: The authors declare no conflict of interest. 


\section{References}

1. Mishra, A.P.; Bajpai, A.; Rai, A.K. 1,4-Dihydropyridine: A Dependable Heterocyclic Ring with the Promising and the Most Anticipable Therapeutic Effects. Mini Rev. Med. Chem. 2019, 19, 1219-1254. [CrossRef] [PubMed]

2. Aygün Cevher, H.; Schaller, D.; Gandini, M.A.; Kaplan, O.; Gambeta, E.; Zhang, F.X.; Çelebier, M.; Tahir, M.N.; Zamponi, G.W.; Wolber, G.; et al. Discovery of Michael acceptor containing 1,4-dihydropyridines as first covalent inhibitors of L-/T-type calcium channels. Bioorganic Chem. 2019, 91, 103187. [CrossRef] [PubMed]

3. Ranjbar, S.; Edraki, N.; Firuzi, O.; Khoshneviszadeh, M.; Miri, R. 5-Oxo-hexahydroquinoline: An attractive scaffold with diverse biological activities. Mol. Divers. 2019, 23, 471-508. [CrossRef]

4. Sahiba, N.; Sethiya, A.; Soni, J.; Agarwal, S. Acridine-1,8-diones: Synthesis and Biological Applications. ChemistrySelect 2021, 6, 2210-2251. [CrossRef]

5. $\quad$ Bai, C.-B.; Wang, N.-X.; Wang, Y.-J.; Lan, X.-W.; Xing, Y.; Wen, J.-L. A new oxidation system for the oxidation of Hantzsch-1,4dihydropyridines and polyhydroquinoline derivatives under mild conditions. RSC Adv. 2015, 5, 100531-100534. [CrossRef]

6. Abdel-Mohsen, H.T.; Conrad, J.; Beifuss, U. Laccase-catalyzed oxidation of Hantzsch 1,4-dihydropyridines to pyridines and a new one pot synthesis of pyridines. Green Chem. 2012, 14, 2686-2690. [CrossRef]

7. Triggle, D.J. Calcium channel antagonists: Clinical uses-Past, present and future. Biochem. Pharmacol. 2007, 74, 1-9. [CrossRef]

8. Wang, B.; Hu, Y.; Hu, H. The Aromatization of Hantzsch 1,4-Dihydropyridines by Tetrakis-Pyridine Cobalt (II) Dichromate (TPCD). Synth. Commun. 1999, 29, 4193-4199. [CrossRef]

9. Kumar, P.; Kumar, A. An Expeditious Oxidative Aromatization of Hantzsch 1,4-Dihydropyridines to Pyridines Using Cetyltrimethylammonium Peroxodisulfate: A Phase Transferring Oxidant. Bull. Korean Chem. Soc. 2010, 31, 2299-2303. [CrossRef]

10. Mirza-Aghayan, M.; Boukherroub, R.; Nemati, M.; Rahimifard, M. Graphite oxide mediated oxidative aromatization of 1,4dihydropyridines into pyridine derivatives. Tetrahedron Lett. 2012, 53, 2473-2475. [CrossRef]

11. Giardina, P.; Faraco, V.; Pezzella, C.; Piscitelli, A.; Vanhulle, S.; Sannia, G. Laccases: A never-ending story. Cell Mol. Life Sci. 2010, 67, 369-385. [CrossRef]

12. Frasconi, M.; Favero, G.; Boer, H.; Koivula, A.; Mazzei, F. Kinetic and biochemical properties of high and low redox potential laccases from fungal and plant origin. Biochim. Biophys. Acta Proteins Proteom. 2010, 1804, 899-908. [CrossRef] [PubMed]

13. Cambria, M.T.; Minniti, Z.; Librando, V.; Cambria, A. Degradation of Polycyclic Aromatic Hydrocarbons by Rigidoporus lignosus and its Laccase in the Presence of Redox Mediators. Appl. Biochem. Biotechnol. 2008, 149, 1-8. [CrossRef] [PubMed]

14. Shariati, M.; Imanzadeh, G.; Rostami, A.; Ghoreishy, N.; Kheirjou, S. Application of laccase/DDQ as a new bioinspired catalyst system for the aerobic oxidation of tetrahydroquinazolines and Hantzsch 1,4-dihydropyridines. Comptes Rendus Chim. 2019, 22, 337-346. [CrossRef]

15. Khaledian, D.; Rostami, A.; Zarei, S.A.; Mohammadi, B. Aerobic oxidative aromatization of Hantzsch 1,4-dihydropyridines via an anomeric-based oxidation in the presence of Laccase enzyme/4-Phenyl urazole as a cooperative catalytic oxidation system. J. Iran. Chem. Soc. 2019, 16, 1871-1878. [CrossRef]

16. Simić, S.; Jeremic, S.; Djokic, L.; Božić, N.; Vujčić, Z.; Lončar, N.; Senthamaraikannan, R.; Babu, R.; Opsenica, I.M.; Nikodinovic-Runic, J. Development of an efficient biocatalytic system based on bacterial laccase for the oxidation of selected 1,4-dihydropyridines. Enzym. Microb. Technol. 2020, 132, 109411. [CrossRef]

17. Kurniawati, S.; Nicell, J.A. Efficacy of mediators for enhancing the laccase-catalyzed oxidation of aqueous phenol. Enzym. Microb. Technol. 2007, 41, 353-361. [CrossRef]

18. Piontek, K.; Antorini, M.; Choinowski, T. Crystal structure of a laccase from the fungus Trametes versicolor at 1.90-A resolution containing a full complement of coppers. J. Biol. Chem. 2002, 277, 37663-37669. [CrossRef]

19. Tadesse, M.A.; D'Annibale, A.; Galli, C.; Gentili, P.; Sergi, F. An assessment of the relative contributions of redox and steric issues to laccase specificity towards putative substrates. Org. Biomol. Chem. 2008, 6, 868-878. [CrossRef]

20. Durão, P.; Chen, Z.; Fernandes, A.T.; Hildebrandt, P.; Murgida, D.H.; Todorovic, S.; Pereira, M.M.; Melo, E.P.; Martins, L.O. Copper incorporation into recombinant CotA laccase from Bacillus subtilis: Characterization of fully copper loaded enzymes. J. Biol. Inorg. Chem. JBIC Publ. Soc. Biol. Inorg. Chem. 2008, 13, 183-193. [CrossRef]

21. Zouraris, D.; Kiafi, S.; Zerva, A.; Topakas, E.; Karantonis, A. FTacV study of electroactive immobilized enzyme/free substrate reactions: Enzymatic catalysis of epinephrine by a multicopper oxidase from Thermothelomyces thermophila. Bioelectrochemistry 2020, 134, 107538. [CrossRef] [PubMed]

22. Gramss, G. Reappraising a Controversy: Formation and Role of the Azodication (ABTS2+) in the Laccase-ABTS Catalyzed Breakdown of Lignin. Fermentation 2017, 3, 27. [CrossRef]

23. Morozova, O.V.; Shumakovich, G.P.; Shleev, S.V.; Yaropolov, Y.I. Laccase-mediator systems and their applications: A review. Appl. Biochem. Microbiol. 2007, 43, 523-535. [CrossRef]

24. Hilgers, R.; Vincken, J.-P.; Gruppen, H.; Kabel, M.A. Laccase/Mediator Systems: Their Reactivity toward Phenolic Lignin Structures. ACS Sustain. Chem. Eng. 2018, 6, 2037-2046. [CrossRef] [PubMed]

25. Zerva, A.; Koutroufini, E.; Kostopoulou, I.; Detsi, A.; Topakas, E. A novel thermophilic laccase-like multicopper oxidase from Thermothelomyces thermophila and its application in the oxidative cyclization of 2,3,4-trihydroxychalcone. New Biotechnol. 2019, 49, 10-18. [CrossRef]

26. Johannes, C.; Majcherczyk, A. Natural Mediators in the Oxidation of Polycyclic Aromatic Hydrocarbons by Laccase Mediator Systems. J. Appl. Environ. Microbiol. 2000, 66, 524-528. [CrossRef] 
27. Galli, C.; Gentili, P.; Jolivalt, C.; Madzak, C.; Vadalà, R. How is the reactivity of laccase affected by single-point mutations? Engineering laccase for improved activity towards sterically demanding substrates. Appl. Microbiol. Biotechnol. 2011, 91, 123-131. [CrossRef]

28. Sitarz, A.K.; Mikkelsen, J.D.; Meyer, A.S. Structure, functionality and tuning up of laccases for lignocellulose and other industrial applications. Crit. Rev. Biotechnol. 2016, 36, 70-86. [CrossRef]

29. Subrahmanyam, V.V.; Kolachana, P.; Smith, M.T. Metabolism of hydroquinone by human myeloperoxidase: Mechanisms of stimulation by other phenolic compounds. Arch. Biochem. Biophys. 1991, 286, 76-84. [CrossRef]

30. Xu, F.; Shin, W.; Brown, S.H.; Wahleithner, J.A.; Sundaram, U.M.; Solomon, E.I. A study of a series of recombinant fungal laccases and bilirubin oxidase that exhibit significant differences in redox potential, substrate specificity, and stability. Biochim. Biophys. Acta Protein Struct. Mol. Enzymol. 1996, 1292, 303-311. [CrossRef]

31. Mehra, R.; Muschiol, J.; Meyer, A.S.; Kepp, K.P. A structural-chemical explanation of fungal laccase activity. Sci. Rep. 2018, 8, 17285. [CrossRef] [PubMed]

32. Glazunova, O.A.; Trushkin, N.A.; Moiseenko, K.V.; Filimonov, I.S.; Fedorova, T.V. Catalytic Efficiency of Basidiomycete Laccases: Redox Potential versus Substrate-Binding Pocket Structure. Catalysts 2018, 8, 152. [CrossRef]

33. Wang, T.-N.; Zhao, M. A simple strategy for extracellular production of CotA laccase in Escherichia coli and decolorization of simulated textile effluent by recombinant laccase. Appl. Microbiol. Biotechnol. 2017, 101, 685-696. [CrossRef]

34. Chen, Y.C. Beware of docking! Trends Pharmacol. Sci. 2015, 36, 78-95. [CrossRef] [PubMed] 